\title{
Growth, Carbon Assimilation and Quality of Kesum (Persicaria minor) as Exposed to Zinc Oxide Nanoparticles
}

\author{
Noor Fatehah Zainuren ${ }^{1}$, Mohd Hafiz Ibrahim $^{1^{*}}$, Che Azurahanim Che Abdullah ${ }^{1}$ \\ and Tuan Syaripah Najihah ${ }^{2}$ \\ ${ }^{1}$ Faculty of Science, Universiti Putra Malaysia, 43400 Serdang Selangor, Malaysia. \\ ${ }^{2}$ School of Agriculture Sciences and Biotechnology, Faculty of Bioresources and Food Industry, \\ Universiti Sultan Zainal Abidin, Besut Campus, 22200 Terengganu, Malaysia.
}

\section{Authors' contributions}

This work was carried out in collaboration among all authors. Author MHI designed the study, performed the statistical analysis, wrote the protocol and wrote the first draft of the manuscript. Authors NFZ and CACA managed the analyses of the study. Author TSN managed the literature searches. All authors read and approved the final manuscript.

Article Information

DOI: $10.9734 / A R R B / 2019 / v 31 i 530062$

Editor(s):

(1) Dr. Rishee K. Kalaria, Assistant Professor,Bioinformatics Section, Aspee Shakilam Biotechnology Institute,Navsari Agricultural University, Surat, India.

(2) Dr. George Perry, Dean and Professor of Biology, University of Texas at San Antonio, USA.

Reviewers:

(1) Toungos, Mohammed Dahiru, Adamawa State University, Nigeria.

(2) Charles Nyambane Onyari, University of Embu, Kenya.

(3) Rajan Bhatt, Punjab agricultural University, India Complete Peer review History: http://www.sdiarticle3.com/review-history/47893

Original Research Article

Received 15 January 2019

Accepted 01 April 2019

Published 30 April 2019

\section{ABSTRACT}

Aims: This study was conducted to investigate the effect of zinc oxide nanoparticles towards the Persicaria minor that can be used as a guidance for further toxicity investigation of ZnO-NPs.

Study Design: A Completely Randomized Block Design (RCBD) was used with three replication. Each unit was consisted with eight plants and the total of 96 plants were used in this study.

Place and Duration of Study: This study was conducted in plot 1, Vegetables Field plot for Teaching and Research, Taman Pertanian Universiti, Universiti Putra Malaysia (UPM) Selangor, Malaysia, from May 2018 until August 2018.

Methodology: Persicaria minor were exposed to four different concentration of zinc oxide nanoparticles (ZnO-NPs) which were $(50,100$ and $150 \mathrm{mg} / \mathrm{L})$ and $0 \mathrm{mg} / \mathrm{L}$ as a control. The $\mathrm{ZnO}-$ 
NPs was dissolved in distilled water before being applied to plants. $40 \mathrm{~mL}$ of ZnO-NPs solution was applied to each plant. The growth, carbon assimilation and also secondary metabolites were measured in this experiment.

Results: The results showed that the treatment of zinc oxide nanoparticles enhanced growth of the Persicaria minor as the plant treated with zinc oxide nanoparticles had higher plant height and total biomass when compared to control treatment. However, the analysis revealed that the treatment of zinc oxide nanoparticles highly and significantly influenced the carbon assimilation and quality of this plant as the treated plants showed reduction in chlorophyll content, photosynthesis rate, stomatal conductance and transpiration rate but increased in production of secondary metabolites. The increased in production of plant secondary metabolites may be attributed by the plant protection mechanism due to metabolic stress caused by high concentration of zinc oxide nanoparticles.

Conclusion: This research will progressively help in contributing some reliable and valid data on the effect of zinc oxide nanoparticles (ZnO-NPs), towards the Persicaria minor that can be used as guidance for further experimental investigation regarding this field.

Keywords: Persicaria minor; zinc- oxide nanoparticles; growth; carbon assimilation; secondary metabolites; toxicity.

\section{INTRODUCTION}

According to National Health Portal [1], the World Health Organization (WHO) estimated that 80 percent of the world's population consume herbal medicine for their health care and there are about 21000 plants species with the potential to be utilized as medicinal plants. Persicaria minor is one of the plants that gained great attention in this field of study. According to Christapher et al. [2], Persicaria minor have gained great attention in scientific study due to its high content of antioxidant. This plant possesses variety of pharmacological properties such as antioxidant activity, antiulcer activity, anti-inflammatory activity, antimicrobial activity, anticancer activity and can enhance the digestive properties and cytotoxic activity [2]. According to Rusdi et al. [3], $P$. minor is locally known as a 'kesum', and is commonly used as a food additive and flavouring agent. Many studies have been carried out because of the popularity of the P.minor as a potential medicinal plant with high antioxidant and antimicrobial activities and strong antiinflammatory properties.

Recently, nanoparticles (NPs) are widely studied because its beneficial properties in agriculture and allied sector [4]. According to them, zinc oxide nanoparticles (ZnO-NPs) is one of NPs used widely as it has been utilized in variety of industrial sector including medication, cosmetic materials, opposed microorganisms and textile industries. As it has been commercially used, the toxicity effect of these ZnO-NPs to the environment and also soil ecosystem are of main concern [5]. Sabir et al. [6] stated that ZnO-NPs possess significant characteristics which have antimicrobial, optical and physical properties therefore it has great potential to enhance agriculture. The presence of $\mathrm{ZnO}-\mathrm{NPs}$ has shown to enhance the antioxidant mechanism that helps to stabilize the plants and improve the photosynthetic efficiency [7]. However, the effect depends on the concentration of $\mathrm{ZnO}-\mathrm{NPs}$ and varies from plant to plant [8-10].

Secondary metabolites are the natural compound that produced by the plants and some of the compound are utilized as medicines, flavoring and drugs. According to Biology Reference [11] the simple classification of plants' secondary metabolites includes three main groups which are terpenes, phenolics and nitrogen- containing compounds. Secondary metabolites do not involve in the plant growth and development but required for plant to survive in the environment because they protect plants from other organisms such as pathogen and herbivores that can harm the plants [10]. These compounds possess significant biological properties and also medicinal importance that can improve pharmaceuticals field [10]. The application of $\mathrm{ZnO}$ nanoparticles might enhances the production of plant secondary metabolites and thus enhanced the medicinal properties of this plant.

Currently, there is no study conducted on the interaction effect of $\mathrm{ZnO}-\mathrm{NPs}$ on physical and biochemical response of plant especially in medicinal plants like Persicaria minor and only few research being carried out to discover about the effect of $\mathrm{ZnO}-\mathrm{NPs}$ on carbon assimilation and production of secondary metabolite of this plant, Hence, the objectives of this study were to study 
the growth, carbon assimilation and quality of Persicaria minor as affected by zinc oxide nanoparticles, to determine the optimum concentration dose of zinc oxide nanoparticles that can enhance the optimum growth and secondary metabolites of Persicaria minor and to recognize the relationship between secondary metabolites and growth of Persicaria minor as exposed by zinc oxide nanoparticles application.

\section{MATERIALS AND METHODS}

\subsection{Experimental Site}

This study was conducted in Plot 1 , Vegetables Field Plot for Teaching and Research, Taman Pertanian Universiti, Universiti Putra Malaysia (UPM) Selangor. The research site was set up with net shading and black plastic to reduce the absorption of water by sunlight since Persicaria minor require high amount of water and also to reduce the competition with grasses and other plants. This experiment was conducted from the month of May 2018 until August 2018. The microclimatic parameters during the experiment are presented in Table 1.

Table 1. The microclimate data during the experiment

\begin{tabular}{ll}
\hline $\begin{array}{l}\text { Microclimate } \\
\text { parameters }\end{array}$ & Quantification \\
\hline Relative humidity & $57.14-68.23 \%$ \\
Light intensity & $320-860 \mu \mathrm{mol} / \mathrm{m} 2 / \mathrm{s}$ \\
Day temperature & $26-34^{\circ} \mathrm{C}$ \\
Night temperature & $16-23^{\circ} \mathrm{C}$ \\
Ambient $\mathrm{CO}_{2}$ & $380.23 \mathrm{ppm}$ \\
\hline
\end{tabular}

\subsection{Planting Material}

Persicaria minor was obtained from Jabatan Pertanian, Serdang. The first internodes at the bottom of the shoots with five number of leaves was cut in $5 \mathrm{~cm}$ in height for the shoot stem cutting preparation. The shoot stem cuttings were immersed in the tap water overnight to increase their turgidity which increases the speed of the germination. Then, the propagation step was done in the trays with peat moss as the medium and the shoots stem cutting were left for two weeks for the development of the root. Then, the plants were transferred into standard polybag $(16 \mathrm{~cm} \times 30 \mathrm{~cm})$ which was filled with top soil as the medium [12].

\subsection{Soil Preparation}

The soil medium was obtained from Unit Herba, Taman Pertanian Universiti and top soil was used as the medium for the Persicaria minor planting. The top soil was transferred into the polybag until it filled three- quarter of the polybag.

\subsection{Synthesis and Properties of Zinc- Oxide Nanoparticles (ZnO-NPs)}

The ZnO-NPs was synthesized chemically in the Laboratory of BioPhysics of Physics Department, Faculty of Science UPM by using sol gel method. In this process in room temperature, $200 \mathrm{ml}$ of ethanol was added to $0.2 \mathrm{M}$ of zinc acetate and then, the mixture was stirred for two hours to obtain clear solution. Then, 1.0 M sodium hydroxide $(\mathrm{NaOH})$ was titrated into the mixture until the $\mathrm{pH} 9$ is reached. After that, the mixture was stirred for one hour and then left for 24 hours to allow the complete hydrolysis and gelation. The sample was then filtrated to obtain white precipitate. The precipitate is dried in an oven for 48 hours at $100^{\circ} \mathrm{C}$ to dry. And lastly, the dried sample was grinded by mortar and pestle to yield $\mathrm{ZnO}$ powder to be used in the experiment.

\subsection{Experimental Design}

A Completely Randomized Block Design (RCBD) was used in this study with three replications. Each unit consisted eight plants and the totals of 96 plants were used in this study. After a month, Persicaria minor was exposed to four different concentration of zinc oxide nanoparticles ( $\mathrm{ZnO}$ NPs) which were $(50,100$ and $150 \mathrm{mg} / \mathrm{L})$ and 0 $\mathrm{mg} / \mathrm{L}$ as a control. The $\mathrm{ZnO}-\mathrm{NPs}$ was dissolved in distilled water before being applied to plants. $40 \mathrm{~mL}$ of $\mathrm{ZnO}-\mathrm{NPs}$ solution was applied to each plant.

\subsection{Plant Maintenance}

The maintenance steps are very crucial to ensure the plant develops healthy and to avoid the plants from wilting or attacked by any disease that can cause the plants to die. At the early phase of cultivation, Persicaria minor were watered two times daily. The watering was unnecessary only when the heavy rain occur. This to avoid the over watering to the plants that can interfere with the plants growth. The common insects that could interfere with the 
plants growth were removed quickly from the planting area.

\subsection{Collection of Data}

The growth data collection was done once a week after the application of treatment for the plant's growth parameter. The destructive analysis and leaf gas exchange of the experiment were conducted at the end of the experiment.

\subsubsection{Plant growth measurements}

The plant growth measurements were conducted to obtain data on plant height, number of leaf and stem, diameter of stem, root to shoot ratio and the chlorophyll content. The plant height was measured starting from the stem on the soil surface until the highest shoot growth using a measuring tape. The plant basal diameter was measured by using vernier caliper at the base of the plants and the leaves of the Persicaria minor were counted manually in every three weeks.

\subsubsection{Chlorophyll content measurement}

The total chlorophyll content of the leaves was measured by using chlorophyll meter (SPAD 502). The leaves of the plants in each treatment for each replication were clipped by chlorophyll meter clipper to obtain the reading.

\subsubsection{Plant fresh weight measurement}

The plants were removed first from the soil and all the dirt were removed under the flowing tap water. Then, the shoot and the root parts were separated for further analysis and all the plants parts were weighted separately using analytical balance.

\subsubsection{Dry weight (biomass) measurement}

The plants were dried in the oven at $60^{\circ} \mathrm{C}$ for 48 hours. Then, the measurements were recorded as observed using electronic weighing scale.

\subsubsection{Root to shoot ratio}

The root to shoot ratio was determined by dividing the weight of the roots part to the shoot part after the oven drying process.

\subsubsection{Plant leaf temperature determination}

The Infrared (IR) thermometer was used to measure the plant leaves temperature. This was to indicate whether the plant under stressful condition or not. The upper leaf part was chosen in the determination [13].

\subsubsection{Leaf gas exchange measurement}

A portable photosynthesis system LI-6400XT (LiCOR Inc; Nebraska; USA) was used to measure the leaf gas exchange. This equipment was warmed and was calibrated with ZERO IRGA mode for 30 minutes. The measurement was set at optimum condition which were $400 \mu \mathrm{mol} \mathrm{mol}^{-1}$ $\mathrm{CO}_{2}, 30^{\circ} \mathrm{C}$ cuvette temperature, $60 \%$ relative humidity with the rate of air flow set at $500 \mathrm{~cm}^{3}$ $\mathrm{min}^{-1}$ and then the cuvette condition was modified at $800 \mu \mathrm{molm}^{-2} \mathrm{~s}^{-1}$ photosynthetically photon flux density (PPFD). The measurement process of gas exchange was carried out between 9.00 am to 11.00 am by using fully expanded young leaves that give the measurement of net photosynthesis (A), stomata conductance (gs) and transpiration rate (E). Water use efficiency (WUE) was measured by using the formula of net photosysthesis dividing with transpiration rate. This is automatic operation and the results were saved in the LI6400XT console and Photosyn Assistant Software (Dundee Scientific, Dundee, UK) was used to analyze it. Precautions were taken to avoid mistakes during taking the measurements [14].

\subsubsection{Total phenolics and flavonoids quantification}

The methods used for extraction and quantification of total phenolics and flavonoids contents followed that described in Ibrahim et al. [15]. A fixed amount of ground tissue samples $(0.1 \mathrm{~g})$ was extracted with $80 \%$ ethanol $(10 \mathrm{~mL})$ on an orbital shaker for $120 \mathrm{~min}$ at $50^{\circ} \mathrm{C}$. The mixture was subsequently filtered (Whatman ${ }^{\mathrm{TM}}$ No.1), and the filtrate was used for the quantification of total phenolics and total flavonoids. Folin-Ciocalteu reagent (diluted 10fold) was used to determine total phenolics content of the leaf samples. The sample extract at $200 \mu \mathrm{L}$ was mixed with Folin-Ciocalteau reagent $(1.5 \mathrm{~mL})$ and allowed to stand at $22^{\circ} \mathrm{C}$ for 5 min before adding $\mathrm{NaNO}_{3}$ solution $(1.5 \mathrm{~mL}$, $\left.60 \mathrm{~g} \mathrm{~L}^{-1}\right)$. After two hours at $22^{\circ} \mathrm{C}$, absorbance was measured at $725 \mathrm{~nm}$. The results were expressed as $\mathrm{mg} \mathrm{g}^{-1}$ gallic acid equivalent (mg GAE $\mathrm{g}^{-1}$ dry sample). For total flavonoids determination, samples $(1 \mathrm{~mL})$ were mixed with $\mathrm{NaNO}_{3}(0.3 \mathrm{~mL})$ in a test tube covered with aluminium foil, and left for $5 \mathrm{~min}$. Then $10 \% \mathrm{AlCl}_{3}$ 
$(0.3 \mathrm{~mL})$ was added followed by addition of $1 \mathrm{M}$ $\mathrm{NaOH}(2 \mathrm{~mL})$. The absorbance was measured at $510 \mathrm{~nm}$ using a spectrophotometer with rutin asa standard (results expressed as $\mathrm{mg} / \mathrm{g}$ rutin dry sample).

\subsubsection{Chlorophyll fluorescence determination}

The chlorophyll fluorometer was used to measure the chlorophyll florescence of the Persicaria minor. The mature leaf tissue was obtained from the Persicaria minor plant that cultivated at $20^{\circ} \mathrm{C}$ in glasshouse exposed with artificial light to give minimum photon flux density of 550 umol m $\mathrm{m}^{-2} \mathrm{~s}^{-1}$ for $16 \mathrm{~h}$ photoperiod and phothosynthetically active radiation were supplied at $250 \mathrm{umol} \mathrm{m}^{-2} \mathrm{~s}^{-1}$ during $16 \mathrm{~h}$ photoperiod [16].

\subsection{Statistical Analysis}

Statistical Package for Social Sciences (SPSS) version 24 was used to analyze the recorded data. A two-way ANOVA Test was conducted to analyze data for all the parameters used in the experiment. Results were significant if the $p$ value level was $\leq 0.05$.

\section{RESULTS AND DISCUSSION}

\subsection{Plant Height}

Fig. 1 depicts the effect of three months treatment of zinc oxide nanoparticles (ZnO-NPs) on the plant height of Persicaria minor. The result from analysis of variance showed that there was a significant effect between different concentration of zinc oxide nanoparticles treatment toward the height of Persicaria minor $(P \leq 0.05)$. From the figure, the increasing of concentration of zinc oxide nanoparticles treatment increased the plant height of Persicaria minor. The highest plant height was recorded in $100 \mathrm{mg} / \mathrm{L}$ on 12 weeks after treatment with mean $26.01 \mathrm{~cm}$ that might indicates the optimum concentration for the plant. Meanwhile, the control treatment recorded the shortest plant height with mean $22.10 \mathrm{~cm}$. The appropriate concentration of zinc oxide nanoparticles plays significant role in plant growth and promotion [15]. From the results, on twelfth week after harvesting, the plants treated with zinc oxide nanoparticles have higher plant height as compared to plants in control treatment. This finding indicates that the application of zinc oxide nanoparticles can induced the growth of the plants. Kouhi et al. [17] explained that the zinc oxide nanoparticles possess plant growth promoting effects and were used as micronutrient fertilizer. The presence of these nanoparticles triggered the physiological processes, acting as growth regulating compound that increased the plant growth such as the plant height and biomass. In addition, Prasad et al. [18] reported that zinc oxide nanoparticles possess beneficial effects in enhancing plant growth and development. The presence of zinc can enhance the biochemical, physiological and anatomical responses of the plants thus increased the plant growth parameters such as plant height and biomass [19]. Therefore, it can be concluded that the zinc oxide nanoparticles treatment induced the plant growth and $100 \mathrm{mg} / \mathrm{L}$ can be considered as the best concentration among the treatments rates in promoting the height of Persicaria minor plant.

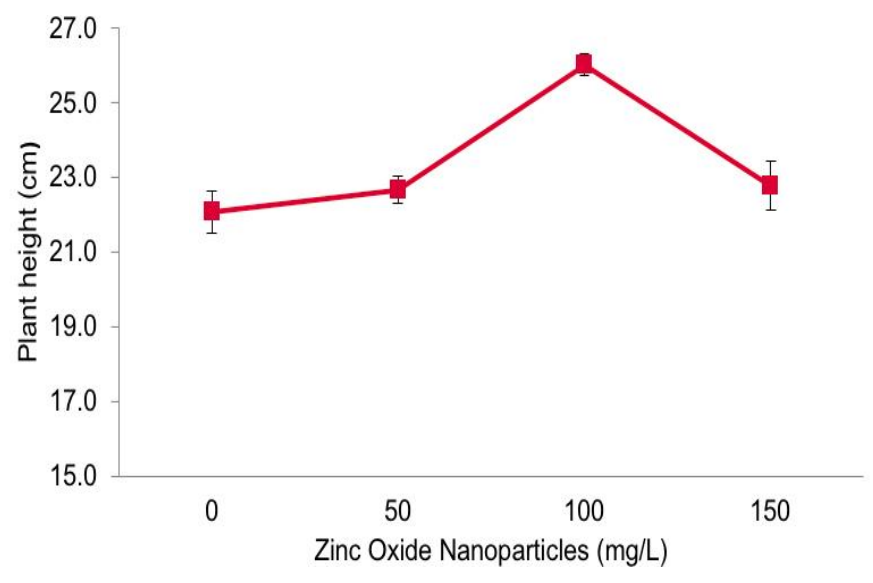

Fig. 1. The effect of zinc oxide nanoparticles treatment $(0,50,100$ and 150$) \mathrm{mg} / \mathrm{L}$ on plant height of Persicaria minor. Data are means with standard error of mean (SEM) of 24 replicates 


\subsection{Plant Leaf Temperature}

Fig. 2 highlights the effect of three months treatment of zinc oxide nanoparticles (ZnO-NPs) on the total leaf temperature of Persicaria minor. The result from the analysis variance showed that there was a significant effect between different concentration of zinc oxide nanoparticles treatment toward the total leaf temperature of Persicaria minor ( $\mathrm{P} \leq 0.05)$. Based on the figure, the trend shows that the plant leaf temperature increases linearly with the concentration of zinc oxide nanoparticles treatment except for the control treatment. This showed that application of Zinc oxide nanoparticles induces stress response to the plants. The plants maintain their most important physiological process (photosynthesis) by maintaining their average leaf temperature at around 21 degrees Celsius [20]. The plants leaf temperature depends on the stomatal conductance and transpiration rates of the plants [21]. Transpiration is one of the best mechanisms used by plants to cool themselves by 'pumping' out water from leaves through stomata [22]. From this study, the increasing of plant leaves temperature can be explained through the reduction of the stomatal conductance and transpiration rates of the plants due to the increase the concentration of the treatment. The reduction in transpiration rate and stomata conductance might be due to the closure of plant stomata under the exposure to the zinc oxide nanoparticles [21]. This high temperature in turns will give negative effect to the photosynthesis process thus affect the plant yields. Therefore, it can be concluded that the zinc oxide nanoparticles treatment increased the plant leaf temperature due to the reduction of stomatal conductance and transpiration rate of Persicaria minor.

\subsection{Total Biomass}

Fig. 3 shows the effect of three months treatment of zinc oxide nanoparticles (ZnO-NPs) on the total biomass of Persicaria minor. The result from the analysis of variance showed that there was a significant effect between different concentration of zinc oxide nanoparticles treatment toward the total biomass of Persicaria minor ( $\mathrm{P} \leq 0.05)$. From the results, it showed that higher concentration of zinc oxide nanoparticles increased the total biomass of Persicaria minor as plants treated with zinc oxide nanoparticles treatment have higher total biomass as compared to the control treatment and $100 \mathrm{mg} / \mathrm{L}$ gave the highest value of total biomass with mean $2.67 \mathrm{~g}$. The highest value of total biomass indicates that $100 \mathrm{mg} / \mathrm{L}$ was the optimum concentration of zinc oxide nanoparticles for Persicaria minor despite 150 $\mathrm{mg} / \mathrm{L}$ that reduced the total biomass of the plant. This study showed that the treatment of zinc oxide nanoparticles increased the plant biomass so the treatment might be effective in boosting the plant growth and yield. Similar finding was observed from study conducted by Venkatachalam et al. [23] that revealed total biomass significantly increased in the zinc oxide nanoparticles treated plants as compared to control. This is also supported by findings of Munir et al. [24] that stated the treatment of zinc oxide nanoparticles increased the shoot and root dry weight thus increased the plant biomass. The presence of zinc can enhance the biochemical, physiological and anatomical responds of the plants thus increased the plant growth such as plant height and biomass [15]. Hence, it can be concluded that the presence of zinc oxide nanoparticles can boost the Persicaria minor growth resulting in increasing of the plant total biomass.

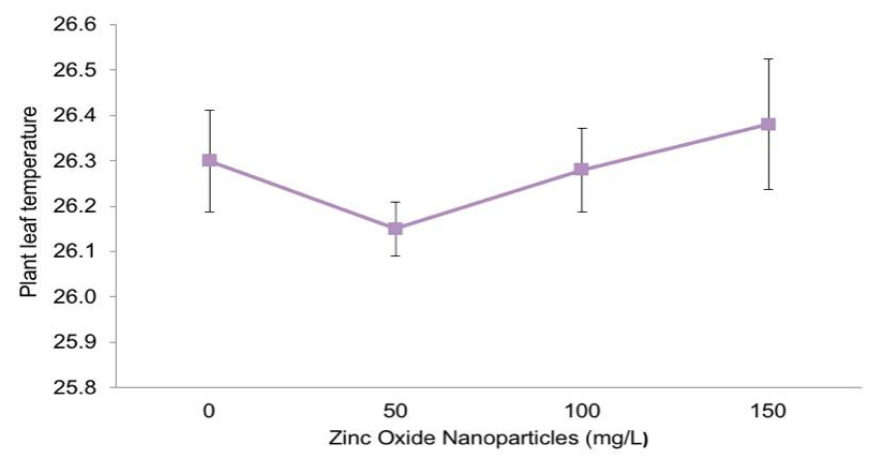

Fig. 2. The effect of zinc oxide nanoparticles treatment $(0,50,100$ and 150$) \mathrm{mg} / \mathrm{L}$ on plant leaf temperature of Persicaria minor. Data are means with standard error of mean (SEM) of 24 replicates 


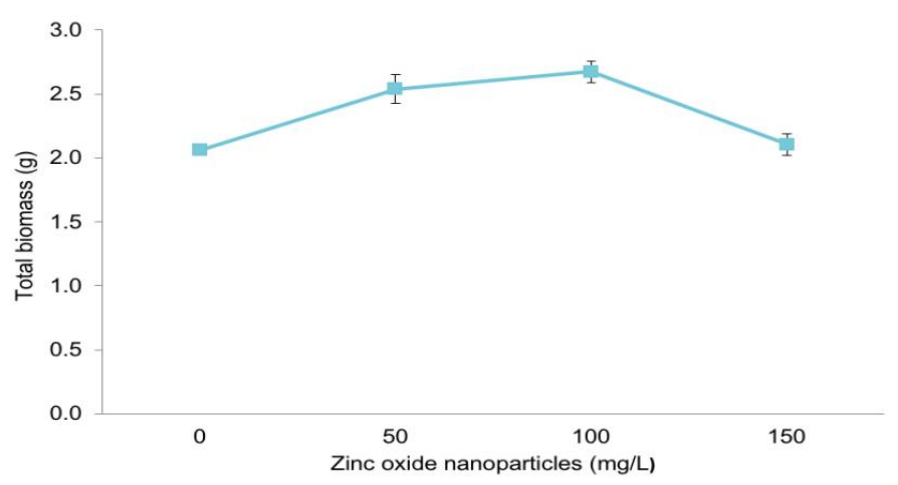

\section{Fig. 3. The effect of zinc oxide nanoparticles treatment $(0,50,100$ and 150$) \mathrm{mg} / \mathrm{L}$ on total biomass of Persicaria minor. Data are means with standard error of mean (SEM) of 24 replicates}

\subsection{Net Photosynthesis Rate (A)}

Fig. 4 illustrated the effect of three months treatment of zinc oxide nanoparticles (ZnO-NPs) on the net photosynthesis rate of Persicaria minor. The exposure of zinc oxide nanoparticles toward the Persicaria minor was highly and significantly affected the net photosynthesis rate of the plant $(P \leq 0.05)$. From the result, the highest photosynthesis rate was recorded in control treatment while the lowest photosynthesis rate was recorded in $150 \mathrm{mg} / \mathrm{L}$ of zinc oxide nanoparticles treatment with mean 6.32 $\mu \mathrm{mo} / \mathrm{m}^{2} / \mathrm{s}$ and $4.00 \mu \mathrm{mo} / \mathrm{m}^{2} / \mathrm{s}$ respectively. From the figure, the photosynthesis rate of the plant reduced with the increasing concentration of zinc oxide nanoparticles treatment. Photosynthesis is the perfect measurement to access plant performance. From this study, the net photosynthesis of Persicaria minor was reduced with the increasing concentration of zinc oxide nanoparticles treatment. Photosynthesis is highly affected in plants that exposed to excess heavy metal where higher level of zinc oxide nanoparticles inhibits the photosynthetic apparatus and caused critical changes to chlorophyll structure and amount [25]. This finding is also similar to that of Wang et al. [26] that revealed the presence of zinc oxide nanoparticles reduced the chlorophyll content in leaves thus reduced the photosynthetic efficiency in plants. In addition, plants exposed to high concentration of zinc oxide nanoparticles have low photosynthetic efficiency might be due to the reduction of chlorophyll content and also excess zinc oxide might damage to the photochemical system [21]. The reduction in photosynthesis with the increased application of zinc oxide was contradicting with the accumulation of total biomass biomass suggesting that $P$. minor adapt to increased level of $\mathrm{Zn}-\mathrm{O}$ nanoparticles by storing more photosynthate for the reduced photosynthetic efficiency. Therefore, it can be concluded that the presence of zinc oxide nanoparticles reduced the photosynthetic efficiency of Persicaria minor plants $[25,26]$.

\subsection{Transpiration Rate (E)}

Fig. 5 depicts the effect of three months treatment of zinc oxide nanoparticles (ZnO-NPs) on the transpiration rate of Persicaria minor. The exposure of different concentration of zinc oxide nanoparticles toward the Persicaria minor highly and significantly affected the transpiration rate of the plant $(P \leq 0.05)$. From the figure, the transpiration rate of the plant reduced with the increasing concentration of zinc oxide nanoparticles treatment. The transpiration rate of $50 \mathrm{mg} / \mathrm{L}$ treatment was significantly higher with mean $2.34 \mathrm{mmol} / \mathrm{m} 2 / \mathrm{s}$ while the lowest transpiration rate of Persicaria minor was observed in $150 \mathrm{mg} / \mathrm{L}$ of zinc oxide nanoparticles treatment with mean $1.42 \mathrm{mmol} / 2 / \mathrm{s}$. Transpiration is a process of the movement of water vapors through plant and this process mainly take place in leaves. Transpiration process is mainly controlled by the opening and closing of the stomata. From the result, the transpiration rate reduced with the increasing concentration of zinc oxide nanoparticles treatment. This finding is similar with Xiaoping et al. [27] that revealed both transpiration rate and stomatal conductance reduced in plants treated with zinc oxide nanoparticles. The stomatal closure reduced the transpiration rate of the plants. According to Vankova et al. [28], the presence of zinc oxide nanoparticles induced the 


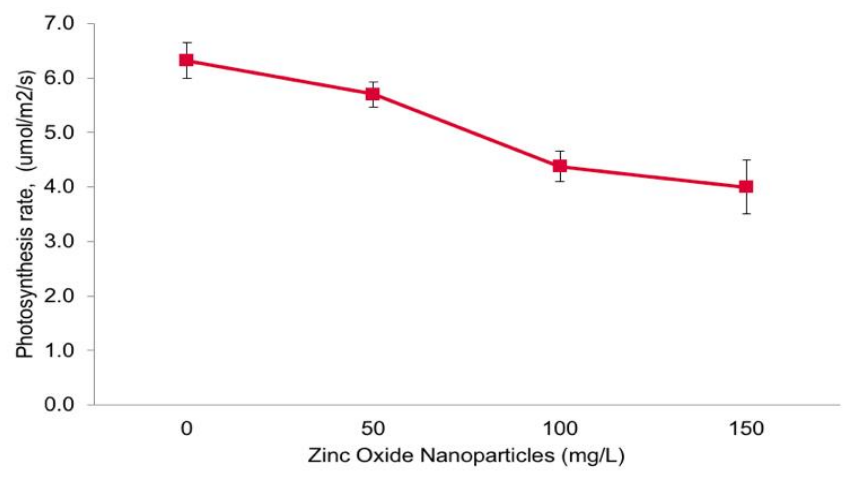

Fig. 4. The effect of zinc oxide nanoparticles treatment $(0,50,100$ and 150$) \mathrm{mg} / \mathrm{L}$ net photosynthesis rate of Persicaria minor. Data are means with standard error of mean (SEM) of 24 replicates

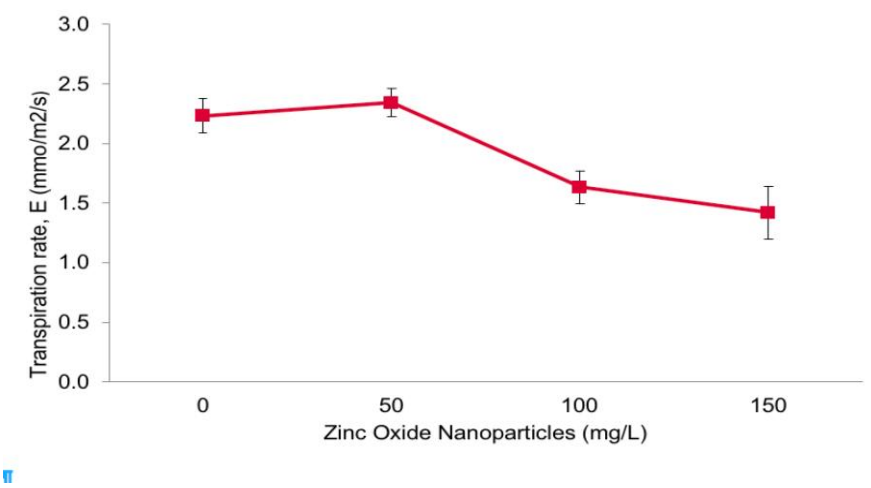

Fig. 5. The effect of zinc oxide nanoparticles treatment $(0,50,100$ and 150$) \mathrm{mg} / \mathrm{L}$ transpiration rate of Persicaria minor. Data are means with standard error of mean (SEM) of 24 replicates

production of plant stress hormone, abscisic acid (ABA) and this hormone mainly accumulated in leaves. The higher level of abscisic acid triggered the stomatal closure which in turn reduced the transpiration rate in plants [29]. Hence, the application of zinc oxide nanoparticles reduced transpiration rate of Persicaria minor might be due to the accumulation of ABA stress hormone that cause the closure of stomata.

\subsection{Stomatal Conductance (GS)}

Stomatal conductance is a measure of the degree of stomatal opening and a good indicator in accessing plant water status [25]. Fig. 6 shows the effect of three months treatment of zinc oxide nanoparticles ( $\mathrm{ZnO}-\mathrm{NPs}$ ) on the transpiration rate of Persicaria minor. The exposure of different concentration of zinc oxide nanoparticles toward the Polygonum minus was highly and significantly affected the stomatal conductance of the plant $(P \leq 0.05)$. From the figure, the stomatal conductance of the plant reduced as the concentration of the zinc oxide nanoparticles treatment increasing. The highest stomatal conductance was recorded in control treatment while the lowest stomatal conductance was observed in $150 \mathrm{mg} / \mathrm{L}$ of zinc oxide nanoparticles treatment with mean 0.43 and 0.07 $\mathrm{mmol} / \mathrm{m} 2 / \mathrm{s}$ respectively. The finding showed reduction in stomatal conductance might due to the increasing of zinc oxide nanoparticles concentration is similar with Xiaoping et al. [27] that proved the higher concentration of zinc oxide nanoparticles reduced the stomatal conductance resulting in low photosynthetic efficiency of the plants. Singh and Bhati [30] also stated that high amounts of zinc oxide nanoparticles can restrict the stomatal conductance. This might due to the toxicity of the treatment disturbed the cell mechanism thus alters the stomatal function. Tsonev and Lidon [31] explained that the stomatal response to high concentration of zinc oxide nanoparticles is related to the changes in 


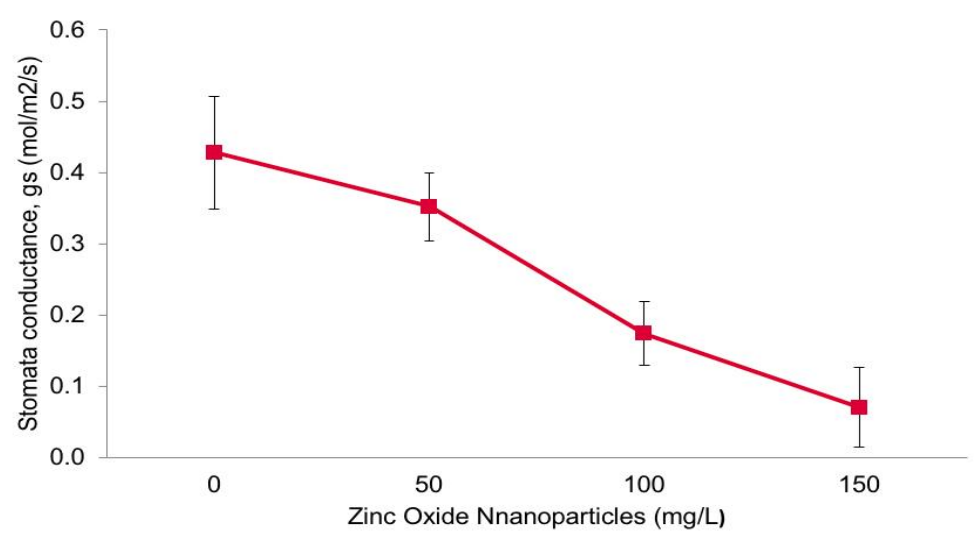

Fig. 6. The effect of zinc oxide nanoparticles treatment $(0,50,100$ and 150$) \mathrm{mg} / \mathrm{L}$ on stomatal conductance of Persicaria minor. Data are means with standard error of mean (SEM) of 24 replicates

carbonic anhydrase (CA) activity. Carbonic anhydrase is an enzyme that is responsible for the stomatal activity and the presence of zinc oxide nanoparticles influenced the CA activity that triggered the stomatal closure thus reduced the stomatal conductance of the plants. Hence, it can be concluded that the presence of zinc oxide nanoparticles alter the stomatal mechanism thus reducing the stomatal conductance of Persicaria minor plants.

\subsection{Maximum Efficiency of Photosystem II}

Fig. 7 depicted the effect of three months treatment of zinc oxide nanoparticles (ZnO-NPs) on the maximum efficiency of photosystem II of Persicaria minor. The exposure of different concentration of zinc oxide nanoparticles toward the Persicaria minor was highly and significantly affected the maximum efficiency of photosystem II of the plant $(P \leq 0.05)$. Based on the figure, increasing the concentration of zinc oxide nanoparticles caused the maximum efficiency of photosystem II to decrease. The highest value of maximum efficiency of photosystem II was observed in control treatment while the lowest value of maximum efficiency of photosystem II was recorded in $150 \mathrm{mg} / \mathrm{L}$ treatment with mean 0.758 and 0.522 respectively. The phytotoxicity of zinc oxide nanoparticles can be accessed through the efficiency of photosynthetic mechanism (chlorophyll florescence) that act as indicator in phytotoxicity assays. The finding of this study revealed that increasing the zinc oxide nanoparticles concentration resulting in lower maximum efficiency of photosystem II of Polygonum minus. Wang et al. [26] stated that the treatment of zinc oxide nanoparticles reduced the chlorophyll florescence parameter and damaged the photochemical system. This finding can be explained further that the presence of zinc oxide nanoparticles induced the oxidative stress in plants and increase the production of reactive oxygen species (ROS) which alter the gene expression pathway thus reduced the chlorophyll florescence in plants. Therefore, it can be concluded that the zinc oxide nanoparticles treatment reduced the chlorophyll florescence parameters of Persicaria minor plants.

\subsection{Maximum Yield of Photosystem II}

Fig. 8 shows the effect of three months treatment of zinc oxide nanoparticles (ZnO-NPs) on the maximum yield of photosystem II of Persicaria minor. The exposure of different concentration of zinc oxide nanoparticles toward the Persicaria minor highly and significantly affected the maximum yield of photosystem II of the plant $(P \leq 0.05)$. The trend shows that increasing the concentration of zinc oxide nanoparticles caused the maximum yield of photosystem II to decrease. Based on the figure, $50 \mathrm{mg} / \mathrm{L}$ of zinc oxide nanoparticles treatment shows the highest value of maximum yield of photosystem II with mean 3.16 when compared with other treatment. From this study, it was observed that the treatment of zinc oxide nanoparticles reduced the maximum efficiency of photosystem II which in turn reduced the maximum yield of photosystem II of Persicaria minor. According to Tsonev and Lidon [31], inside the chloroplast lamellae, the presence of zinc oxide nanoparticles caused the inhibition of photosynthetic electron transport and 
implicates the water evolving complex of photosystem II thus inhibits the photolysis and oxygen emission that disturb the conformation of photosystem II core complex. This mechanism explained how the zinc oxide nanoparticles treatment reduced the efficiency and yield of photosystem II in plants. Hence, the treatment of zinc oxide nanoparticles reduced the maximum yield and efficiency of photosystem II which in turn disturbed the photosynthetic process of Persicaria minor plant.

\subsection{Minimal Florescence}

Fig. 9 shows the effect of three months treatment of zinc oxide nanoparticles ( $\mathrm{ZnO}-\mathrm{NPs}$ ) on the minimal florescence of Persicaria minor. The exposure of different concentration of zinc oxide nanoparticles toward the Polygonum minus highly and significantly affected the maximum yield of photosystem II of the plant $(P \leq 0.05)$. The result showed that higher concentration of zinc oxide nanoparticles treatment resulted in higher value of minimal florescence of Persicaria minor. The highest value of minimal inflorescence was recorded in $150 \mathrm{mg} / \mathrm{L}$ with mean 627.23 while the lowest value was observed in $50 \mathrm{mg} / \mathrm{L}$ with mean 462.67. Higher minimal florescence indicates higher heat dissipation of plants. This might due to the presence of zinc oxide nanoparticles that induced stress in plants thus caused plants to produce high amount of heat. From this study, the treatment of zinc oxide nanoparticles reduced the transpiration rate of Persicaria minor. This reduction might be related with the increasing of minimal florescence of the plants [32]. The high minimal florescence can cause heat stress to the plants. Heat stress is defined as the increase temperature beyond the threshold level that cause damage to plant growth and development [27]. Therefore, it can be deduced that the treatment of zinc oxide nanoparticles increased the minimal florescence of Persicaria minor due to the reduction in transpiration rate of the plants.

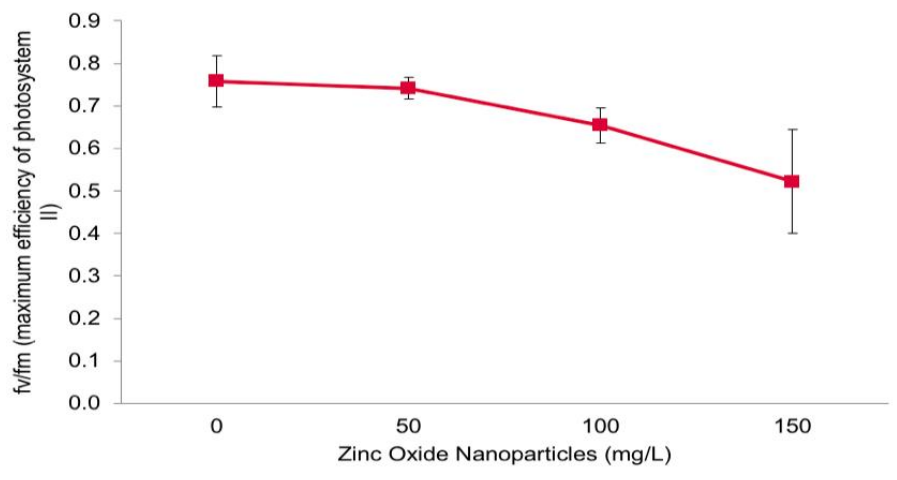

Fig. 7. The effect of zinc oxide nanoparticles treatment $(0,50,100$ and 150$) \mathrm{mg} / \mathrm{L}$ on maximum efficiency of photosystem II of Persicaria minor. Data are means with standard error of mean (SEM) of 24 replicates

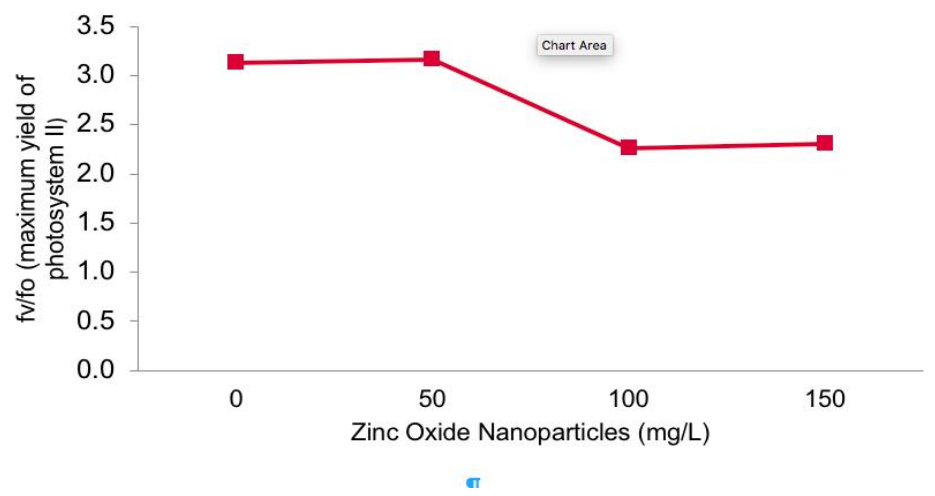

Fig. 8. The effect of zinc oxide nanoparticles treatment $(0,50,100$ and 150$) \mathrm{mg} / \mathrm{L}$ on maximum yield of photosystem II of Persicaria minor. Data are means with standard error of mean (SEM) of 24 replicates 


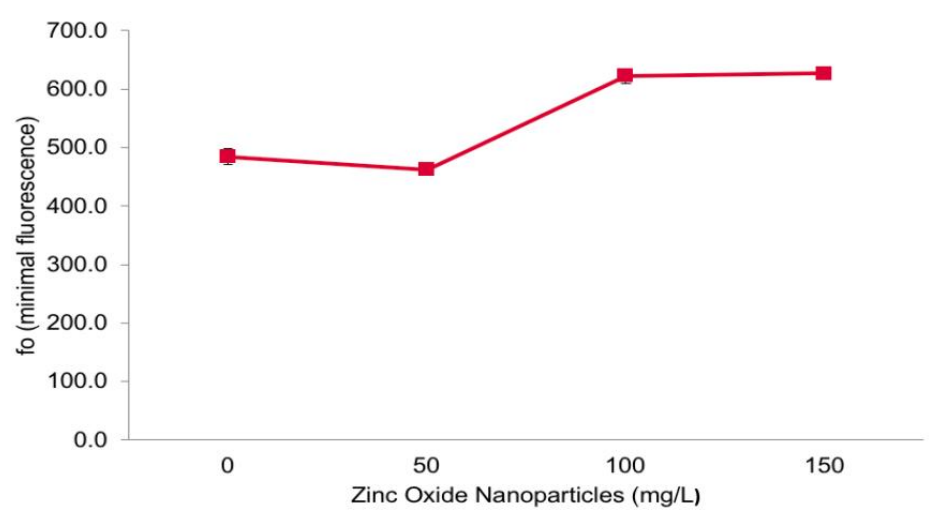

Fig. 9. The effect of zinc oxide nanoparticles treatment $(0,50,100$ and 150$) \mathrm{mg} / \mathrm{L}$ on minimal florescence of Persicaria minor. Data are means with standard error of mean (SEM) of 24 replicates

\subsection{Performance Index (PI)}

Fig. 10 indicated the effect of three months treatment of zinc oxide nanoparticles (ZnO-NPs) on the performance index of Persicaria minor. The exposure of different concentration of zinc oxide nanoparticles toward the Polygonum minus was highly and significantly affected the performance index of the plant $(P \leq 0.05)$. Based on the figure, the highest and lowest performance index were observed in control treatment and $150 \mathrm{mg} / \mathrm{L}$ of zinc oxide nanoparticles treatment with mean 2.42 and 1.50 respectively. The performance index of Persicaria minor reduced when treated with higher concentration of zinc oxide nanoparticles that indicates zinc oxide nanoparticles increased the plant stress. Performance index is an indicator of PSIl functioning and informs about efficiency of assimilating apparatus. It is correlated with water accessibility for plants. High
PI value implies favorable plant condition, and, by analogy, plant have less stress [32]. Nanoparticles such as zinc oxide and silver were located on the surface of plants cells and induced the oxidative stress to the cells by the activation of oxidative stress signaling [28]. From this study, it was observed that the treatment of zinc oxide nanoparticles reduced the plants performance index. Zahed et al. [33] stated that the generation of reactive oxygen species (ROS) due to the zinc oxide nanoparticles treatment alter the gene expression and cell mechanism which in turn reduced the performance index of the plants. Wang et al. [26] explained that the toxicity of zinc oxide nanoparticles reduced chlorophyll content plants, resulted in low photosynthesis efficiency thus reduced the plants performance. Hence, it can be concluded that the presence of zinc oxide nanoparticles induced stress in Persicaria minor resulting in low performance index of the plants.

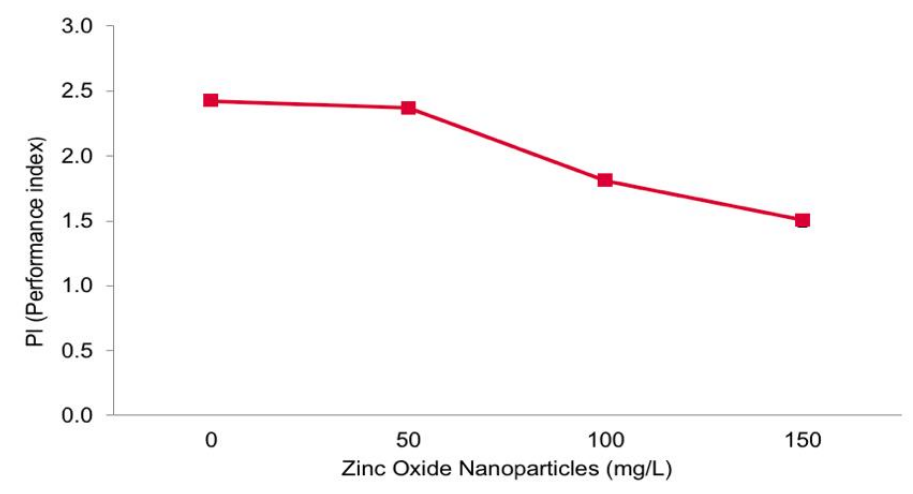

Fig. 10. The effect of zinc oxide nanoparticles treatment $(0,50,100$ and 150$) \mathrm{mg} / \mathrm{L}$ on performance index of Persicaria minor. Data are means with standard error of mean (SEM) of 24 replicates 


\subsection{Total Phenolics Content}

Phenolics are compound that produced by plants to protect plants against stress. This compound plays significant role in plant development (lignin and pigment biosynthesis) and also provided structural integrity for plant's support [34]. Fig. 11 shows the effect of three months treatment of zinc oxide nanoparticles (ZnO-NPs) on the total phenolics production of Persicaria minor. The exposure of different concentration of zinc oxide nanoparticles toward the Polygonum minus highly and significantly affected the total phenolics production of the plant $(P \leq 0.05)$. Based on the figure, the total phenolics production of the plant was directly proportional with the concentration of zinc oxide nanoparticles treatment. The lowest total phenolics production was recorded in control treatment while the highest total phenolics production was recorded in $150 \mathrm{mg} / \mathrm{L}$ treatment with mean 1.44 and 3.82 $\mathrm{GAE} / \mathrm{g}$ dry weight respectively. This result indicates that zinc oxide nanoparticles treatment induced stress and increased the secondary metabolites production of Persicaria minor. From this study, the greater production of total phenolics content in Polygonum minus with the increasing of concentration treatment revealed that the presence of zinc oxide nanoparticles induced stress towards the plants. This finding is supported by Rastogi et al. [35] stated that zinc oxide nanoparticles treatment induced the Reactive Oxygen Species (ROS) production in plants thus increased plants stress. They also stated that higher concentration of zinc oxide nanoparticles leads to the damage of plant cell wall and plasma membrane thus induced the production of plant secondary metabolites for plants defense against disease and threat [36].
Therefore, it can be concluded that higher concentration of zinc oxide nanoparticles lead to plant stress and boost the plants secondary metabolites production which in turn can enhanced the defense response of Persicaria minor plants.

\subsection{Total Flavonoids Content}

Flavonoids are a wide group of plants chemicals (phytonutrients) that found mostly in fruits and vegetables. Flavonoids plays significant role in pharmacological field since this compound is a good source of antioxidant and antiinflammatory, protect skin, enhanced brain function and also good for blood pressure regulation [33]. Fig. 12 shows the effect of three months treatment of zinc oxide nanoparticles (ZnO-NPs) on the total flavonoids production of Persicaria minor. The exposure of different concentration of zinc oxide nanoparticles toward the Persicaria minor highly and significantly affected the total flavonoids production of the plant $(P \leq 0.05)$. Based on the figure, the total flavonoids production of the plant was directly proportional with the concentration of zinc oxide nanoparticles treatment. The lowest total flavonoids production was recorded in control treatment while the highest total flavonoids production was recorded in $150 \mathrm{mg} / \mathrm{L}$ treatment with mean 0.43 and $1.47 \mathrm{mg}$ rutin/g dry weight respectively. This result indicates that zinc oxide nanoparticles treatment induced stress and increased the secondary metabolites production of Persicaria minor. From this study, the greater production of total flavonoids content in Polygonum minus with the increasing of concentration treatment revealed that the presence of zinc oxide nanoparticles induced

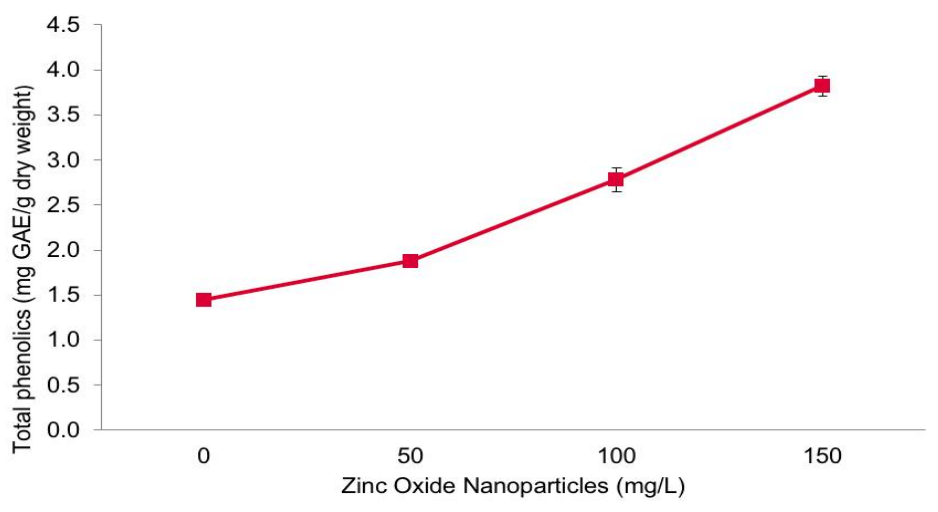

Fig. 11. The effect of zinc oxide nanoparticles treatment $(0,50,100$ and 150$) \mathrm{mg} / \mathrm{L}$ on total phenolics production of Persicaria minor. Data are means with standard error of mean (SEM) of 24 replicates 


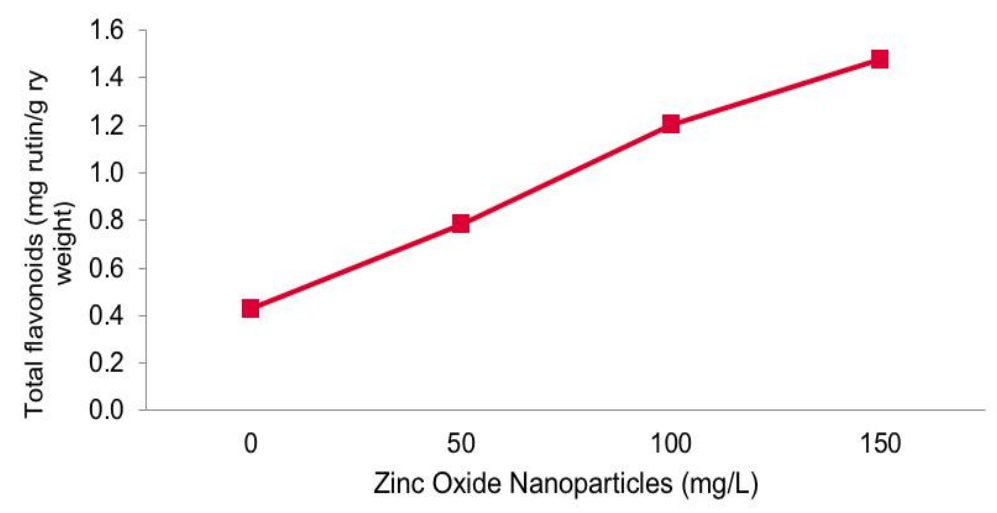

Fig. 12. The effect of zinc oxide nanoparticles treatment $(0,50,100$ and 150$) \mathrm{mg} / \mathrm{L}$ on total flavonoids production of Persicaria minor. Data are means with standard error of mean (SEM) of 24 replicates

stress towards the plants. This finding is similar with that of Zafar et al. [37] where the higher treatment concentration of zinc oxide nanoparticles generates oxidative stress of plants thus increasing the plant secondary metabolites production to protect plants against stress. The initial response of plants towards the presence of nanoparticles involved the increasing level of reactive oxygen species (ROS), cytoplasmic $\mathrm{Ca}^{2 \mathrm{t}}$ and up regulation of nitrogen activated protein kinase (MAPK) cascades thus activates the plants secondary metabolites that act against stress to protect the plants [38]. In addition, the presence of zinc oxide nanoparticles enhanced the expression of genes related to antioxidant capacity thus boost the defense mechanism of the plants by enhancing the production of plants secondary metabolites. Hence, it can be concluded that the presence of zinc oxide nanoparticles enhanced the Persicaria minor secondary metabolites production by increasing the total flavonoids production of the plants.

\section{CONCLUSION}

From this study, it can be concluded that the optimum concentration of zinc oxide nanoparticles for Persicaria minor growth was at $100 \mathrm{mg} / \mathrm{L}$ because it recorded the highest value in the growth parameters. Overall, the treatment of zinc oxide nanoparticles increased the growth parameter of the plants as the treated plants showed higher value of plant height and total biomass when compared to plants in control treatment. However, the treatment of zinc oxide reduces the leaf gas exchange and chlorophyll fluorescence properties of Persicaria minor plants. Despite reduction on the leaf gas exchange and chlorophyll fluorescence the production of secondary metabolites (total phenolics and flavonoids production) were enhanced with increased levels of Zinc oxide application.

\section{COMPETING INTERESTS}

Authors have declared that no competing interests exist.

\section{REFERENCES}

1. National Health Portal. Introduction and Importance of Medicinal Plants and Herbs; 2016.

(Accessed 8 July 2018)

Available:https://www.nhp.gov.in/introducti on-and-importance-of-medicinal-plantsand-herbs_mtl

2. Christapher PV, Parasuraman $S$, Christina JMA, Asmawi MZ, Vikneswaran M. Review on Polygonum minus. Huds, a commonly used food additive in Southeast Asia. Pharmacognosy Research. 2015;7(1):1-6.

3. Rusdi NA, Goh HH, Sabri S, Ramzi AB, Mohd NN, Baharum SN. Functional characterisation of new sesquiterpene synthase from the Malaysian herbal plant, Polygonum minus. Molecules. 2018;23: 1370.

4. Mirzaei $H$, Darroudi M. Zinc oxide nanoparticles: Biological synthesis and biomedical applications. Journal of Ceramics International. 2016;43(1):907914.

DOI:https://doi.org/10.1016/j.ceramint.2016 .10.051. 
5. Vishnu DR, Minkina T, Yaning C, Sushkova S, Chapligin VA, Mandzhieva S. A review on salinity adaptation mechanism and characteristics of Populus euphratica, a boon for arid ecosystems. Acta Ecológica Sinica. 2016;36(6):497-503.

6. Sabir S, Arshad M, Sunbal KC. Zinc Oxide nanoparticles for revolutionizing agriculture: Synthesis and applications. Scientific World Journal. 2014;8. DOI:https://dx.doi.org/10.1155\%2F2014\%2 F925494

7. Faizan $M$, Faraz $A$, Yusof $M$, Khan $M$, Hayat S. Zinc oxide nanoparticle-mediated changes in photosynthetic efficiency and antioxidant system of tomato plants. Journal of Springer. 2017;56(2):678686.

DOI:https://doi.org/10.1007/s11099-0170717-0

8. Manzer HS, Waibi MH, Firoz M, Mutahhar YAK. Role of nanoparticles in plants; 2015. (Accessed 18 February 2018). Available:file:///C:/Users/User/Downloads/9 783319145013-c2.pdf

9. Biology Reference. Secondary Metabolites in Plants; 2018.

(Accessed 13 July 2018)

Available:http://www.biologyreference.com/

Re-Se/Secondary-Metabolites-in

Plants.html

10. Schater $H$, Wink M. Medicinally important secondary metabolites in recombinant microorganisms or plants: Progress in alkaloid biosynthesis. Journal of Biotechnol. 2009;4(12):1684-1703.

DOI: 10.1002/biot.200900229

11. Ibrahim MH, Nurul NM, Zain NAM. Growth, carbon assimilation and biochemical changes of Polygonum minus Huds. as affected by nitrogen fertilization. Jounal of Annual Research and Review in Biology. 2018;26(1):1-17.

12. Paripark $\mathrm{R}$, Sutichai $\mathrm{S}$, Sutee C. $\mathrm{ZnO}$ nanoparticles affect differently the morphological and physiological responses of riceberry plants (Oryza sativa L.). SNRU Journal of Science and Technology. 2018; 10(1):75-81.

13. Amiro BD, Thurtell GW, Gillepie TJ. A small infrared thermometer for measuring leaf temperature in leaf chambers. Journal of Experimental Botany. 1983;11(1):15691576.

14. Makino A. Photosynthesis, grain yield, and nitrogen utilization in rice and wheat. Plant Physiology. 2011;155:125-129.
15. Ibrahim $\mathrm{MH}$, Jaafar $\mathrm{HZE}$, Rahmant $\mathrm{A}$, Rahman Z. Effects of nitrogen fertilization on synthesis of primary and secondary metabolites in three varieties of kacip Fatimah (Labisia pumila Blume). Int. J. Mol Sci. 2011;12(8):5238-525.

16. Boussadia K, Steppe K, Labeke MC, Lemeur R, Braham M. Effects of nitrogen deficiency on leaf chlorophyll fluorescence parameters in two olive tree cultivars Meski' and 'Koroneiki'. J. Plant Nutr. 2015;76:2230-2246.

17. Kouhi SMM, Lahouti M, Ganjeali A, Entezari $\mathrm{MH}$. Comparative phytotoxicity of $\mathrm{ZnO}$ nanoparticles, $\mathrm{ZnO}$ microparticles and $\mathrm{Zn} 2 \mathrm{t}$ on rapeseed (Brassica napus L.): investigating a wide range of concentration. Toxicology and Environmental Chemisty. 2014;96(6):861868.

18. Prasad TNVKV, Sudhakar Y, Sieenivasulu $\mathrm{P}$, Latha V, Munaswamy K, Raja RJS, Sreeprasad PR, Sajanlal Pradeep T. Effect of nanosclae zinc oxide nanoparticles on germination, growth and yield of peanut. Journal of Plant Nutrition. 2012;35:905927.

19. Vishnu DR, Tatiana MM, Arvind B, Svetlana NS, Saglar M, Ritu S, Andrey G, Viktoriia ST, William OP, Karen AG, Hamshik SM. Effects of zinc-oxide nanoparticles on soil, plants, animals and soil organisms: A review. Environmental Nanotechnology, Monitoring and Mangement. 2018;9:76-84.

20. Ledford H. Leaves keep their cool; 2008. (Accessed 13 November 2018)

Available:https://www.nature.com/news/20 08/080611/full/news.2008.884.html

21. Urban J, Miles WI, McGuire MA, Teskey RO. Increase in leaf temperature open stomata and decouples net photosynthesis from stomatal conductance in Pinus taeda and Populus deltoids $x$ nigra. Journal of Experimental Botany. 2017;68(7):17571767.

22. Harlequin G. Plants in high temperature; 2016.

(Accessed 13 November 2018)

Available:http://www.harlequinsgardens.co $\mathrm{m} / \mathrm{mikls}$-articles/plants-in-hightemperatures/

23. Venkatachalam $\mathrm{P}$, Priyanka N, Manikandan K, Ganeshbaru I, Indiraarulselvi $\mathrm{P}$, Geetha N, Muralikrishna K, Bhattacharya RC, Tiwari M, Sharma N, Sahi SV. Enhanced plant growth promoting 
role of phycomolecules coated zinc oxide nanoparticles with $\mathrm{P}$ supplementation in cotton (Gossypium hirsutum L.). Plant Physiology and Biochemistry. 2017;110: 118-127.

24. Munir T, Rizwan M, Kashif M, Shahzad A, Ali S, Amin N, Zahid R, Alam MFE, Imran $M$. Effect of zinc oxide nanoparticles on the growth and zinc uptake in wheat (Triticum aestivum L.) by seed priming method. Digest Journal of Nanomaterials and Biostructures. 2018;13(1):315-32.

25. Tsonev T, Lidon FJC. Zinc in plantsan overview. American Journal Food Agriculture. 2012;24(4):322-333.

26. Wang XP, Li QQ, Pei ZM, Wang SC. Effects of zinc oxide nanoparticles on the growth, photosynthetic traits and antioxidative enzymes in tomato plants. Biological Plantarum. 2018;1-8.

27. Xiaoping W, Chen S, Xiyu Y, Shucai W. Zinc oxide nanoparticles affect the biomass accumulation and photosynthesis in Arabidopsis. Frontiers Plant Science; 2016.

DOI: 10.3389/fpls.2015.01243

28. Vankova R, Lamda P, Podlipna R, Dobrey PT, Prerostova S, Langjansova L, Gaudinova A, Motkova K, Knirsch V, Vanek $\mathrm{T}$. ZnO nanoparticles effects on hormonal pools in Arabidopsis Thaliana. Science Total Environment. 2017;593-594.

29. Gimenez C, Gallordo M, Thompson RB. Plant-water relations. Earth System and Environmental Science. 2013;231-238.

30. Singh G, Bhati M. Mineral toxicity and physiological functions in tree seedling irrigated with effluents of varying chemistry in sandy soil of dry region. Journal of Environmental Science. 2003;21(1): 45-63.

31. Tsonev T, Lidon, FJC. Zinc in plants- an overview. American Journal Food Agriculture. 2012;24(4):322-333.

32. Nahla $\mathrm{SH}$, Taher ASED, Mohamed $\mathrm{HH}$, Ibrahim HB, Asmaa AM. Magnetic and zinc oxide nanoparticles alleviated heat stress in wheat plants. Current Nanomaterials. 2018;3(1):32-43.

33. Zahed H, Ghazala M, Komatsu S. Plant's responses to nanoparticles stress. International Journal of Molecular Science. 2015;16(11):26644-26653.

34. Bhattacharya A, Sood P, Citovsky V. The roles of plant phenolics in defense and communication during Agrobacterium and Rhizobium infection. Molecular Plant Pathology. 2010;11(5):705-719.

35. Rastogi A, Zivcak M, Sytar O, Kalaji HM, Xiaolan H, Mbarki S, Brestic M. Impact of metal and metal oxide nanoparticles on plant: a critical review. Frontiers in Chemistry. 2017;5:78.

36. Szalay S. What are flavonoids? 2015. (Accessed 13 November 2018) Available:https://www.livescience.com/525 24-flavonoids.html

37. Zafar H, Ali A, Ali JS, Haq IU, Zia M. Effect of $\mathrm{ZnO}$ nanoparticles on Brassica seedlings and stem explants: growth dynamics and antioxidate response. Frontiers Plants Science. 2016;7:535.

38. Marslin G, Sheeba CJ, Franklin G. Nanoparticles alter secondary metabolism in plants via ROS burst. Frontiers in Plant Science. 2017;8:832.

(c) 2019 Zainuren et al.; This is an Open Access article distributed under the terms of the Creative Commons Attribution License (http://creativecommons.org/licenses/by/4.0), which permits unrestricted use, distribution, and reproduction in any medium, provided the original work is properly cited. 